\title{
STUDY OF AEROSOL OPTICAL PROPERTIES OVER TWO SITES IN THE FOOTHILLS OF THE CENTRAL HIMALAYAS
}

\author{
D. Rupakheti ${ }^{1 *}$, S. Kang ${ }^{1,2 *}$, Z. Cong ${ }^{3,2}$, M. Rupakheti ${ }^{4}$, L. Tripathee ${ }^{1}$, A. K. Panday ${ }^{5}$, B. Holben ${ }^{6}$ \\ ${ }^{1}$ State Key Laboratory of Cryospheric Science, Northwest Institute of Eco-Environment and Resources, Chinese Academy of \\ Sciences CAS Lanzhou, China \\ ${ }^{2}$ Center for Excellence in Tibetan Plateau Earth Sciences, CAS Beijing, China \\ ${ }^{3}$ Institute of Tibetan Plateau Research, CAS Beijing, China \\ ${ }^{4}$ Institute for Advanced Sustainability Studies (IASS), Germany \\ ${ }^{5}$ International Centre for Integrated Mountain Development (ICIMOD), Lalitpur, Nepal \\ ${ }^{6}$ NASA Goddard Space Flight Center, Greenbelt, Maryland, USA \\ *Corresponding authors': drupakheti2@gmail.com (DR) \& Shichang.kang@1zb.ac.cn (SK) \\ WG III/8- Remote Sensing of Atmospheric Environment
}

KEY WORDS: AOD, angstrom exponent, urban, industrial, biomass burning, Central Himalayas

\begin{abstract}
:
Atmospheric aerosol possesses impacts on climate system and ecological environments, human health and agricultural productivity. The environment over Himalayas and Tibetan Plateau region are continuously degraded due to the transport of pollution from the foothills of the Himalayas; mostly the Indo-Gangetic Plain (IGP). Thus, analysis of aerosol optical properties over two sites; Lumbini and Kathmandu (the southern slope of central Himalayas) using AERONET's CIMEL sun photometer were conducted in this study. Aerosol optical depth (AOD at $500 \mathrm{~nm}$ ), angstrom exponent ( $\alpha$ or AE), volume size distribution (VSD), single scattering albedo (SSA) and asymmetry parameter (AP) were studied for 2013-2014 and the average AOD was found to be: $0.64 \pm 0.41$ (Lumbini) and $0.45 \pm 0.30$ (Kathmandu). The average $\mathrm{AE}$ was found to be: $1.25 \pm 0.24$ and $1.26 \pm 0.18$ respectively for two sites. The relation between $\mathrm{AOD}$ and $\mathrm{AE}$ was used to discriminate the aerosol types over these sites which indicated anthropogenic, mixed and biomass burning origin aerosol constituted the major aerosol types in Lumbini and Kathmandu. A clear bi-modal distribution of aerosol volume size was observed with highest volume concentration during the post-monsoon season in fine mode and premonsoon season in coarse mode (Lumbini) and highest value over both modes during pre-monsoon season in Kathmandu. The single scattering albedo (SSA) and asymmetry parameter (AP) analyses suggested aerosols over the Himalayan foothills sites are dominated by absorbing and anthropogenic aerosols from urban and industrial activities and biomass burning. Long-term studies are essential to understand and characterize the nature of aerosol over this research gap zone.
\end{abstract}

\section{INTRODUCTION}

Atmospheric aerosols of both natural and anthropogenic origins possesses deleterious impacts on climate system, ecological environments, human health and agricultural productivity. However, due to inadequate knowledge about the physical, optical and chemical properties of anthropogenic aerosols (Kaufman et al., 2002), a large source of uncertainty exists in understanding the role of aerosols in the climate system (Stocker et al., 2013). The main reason why scientific understanding of aerosols is still limited, particularly in downwind regions of highly polluted regions of Asia in both temporal and spatial scales are due to the complex aerosol optical and microphysical properties over a wide range (Srivastava et al., 2011).

The Himalayas and Tibetan Plateau are still one of the most pristine regions in the world. But the environment over these regions are continuously degraded due to the transport of pollution from the foothills of the Himalayas; mostly the Indo-Gangetic Plain (IGP) region. Past studies have already shown that the anthropogenic aerosols can alter regional climate, hydrological cycle, clouds and precipitation (Ramanathan et al., 2001; Rosenfeld, 2000). The IGP region or the foothills of the central Himalayas is one of the most populated, polluted and heavily aerosol-laden regions of the world, which also affects the downwind regions like the foothills of the Himalayas and Tibetan Plateau (Ganguly et al., 2006; Gautam et al., 2011; Srivastava et al., 2011). The IGP is often covered in recurrent thick layers of regional air pollution blanket during dry season every year, commonly referred to as Atmospheric Brown Clouds (ABC) (Ramanathan and Crutzen, 2003). Major sources of air pollution in the IGP are biomass burning (Habib et al., 2006), vehicles and industries (Ram and Sarin, 2011), as well as desert dust during pre-monsoon season.

2. STUDY SITES 
In this study, we have analyzed the general optical properties of the aerosols over two important locations from the foothills of the central Himalayas; Lumbini and Kathmandu. In general, Lumbini lies in the northern edge of the central IGP whereas Kathmandu is a valley at the foothills of the central Himalayas. Both of these locations have gained popularity as the places of historical significance with Lumbini being the birthplace of Lord Buddha. However, recently, both of the sites have gained popularity as one of the polluted regions in south Asia. More on these sites have already been explained elsewhere (Rupakheti et al., 2017; Rupakheti et al., 2018; Tripathee et al., 2017).

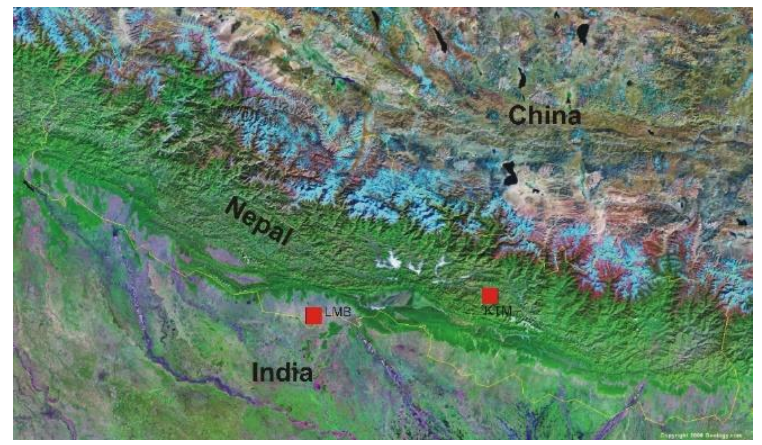

Figure 1. Location of the study sites, LMB and KTM refers to Lumbini and Kathmandu respectively (obtained and modified from www.geology.com).

\section{INSTRUMENTATION}

As an important contribution to SusKat measurement campaign in Nepal, NASA's Aerosol Robotic Network (AERONET, http://aeronet.gsfc.nasa.gov/) project deployed CIMEL sun/sky radiometer in the study area. The sunphotometer makes automatic measurements of direct-sun irradiance and sky radiance in eight spectral channels $(340$, $380,440,500,675,870,940$ and $1020 \mathrm{~nm})$ to determine atmospheric transmission and scattering properties (Holben et al., 1998). Data from the AERONET are available in three levels - Level 1.0 (unscreened), Level 1.5 (cloud screened) and Level 2.0 (quality assured data). In this study, we have used the Level 2.0 data collected between January 2013 and December 2014. Good quality data were obtained for most seriously polluted seasons like pre-monsoon and postmonsoon when agro-residue fires and forest fires, and agroresidue fires, respectively, are prevalent in the region.

\section{RESULTS AND DISCUSSIONS}

Average AOD during the study period was found to be $0.64 \pm 0.41$ (Lumbini) and $0.45 \pm 0.30$ (Kathmandu). It was observed that the AOD levels over Lumbini were lower than in Delhi (0.82) (Sharma et al., 2014) but similar to Kanpur (0.62) (Kedia et al., 2014) whereas the AOD over Kathmandu was found to be still lower as compared to other sites. In Lumbini, total mode, fine mode and coarse mode average AOD were $0.64,0.54$ and 0.10 respectively for the whole study period whereas that observed in Kathmandu was lower with the values of $0.45,0.36$ and 0.09 respectively.
The average fine mode fraction $(84 \%$ and $80 \%$ respectively for Lumbini and Kathmandu) indicates that the larger region (not only in IGP but also beyond) over the foothills of the southern slope of the central Himalaya possess similar FMF value. Regarding the angstrom exponent (AE), average $\mathrm{AE}$ was found to be: $1.25 \pm 0.24$ and $1.26 \pm 0.18$ respectively for two sites. A higher AE value indicates the dominance of fine particles mostly from the combustion-related anthropogenic sources, whereas lower values indicate the dominance of coarse particles like desert dust and sea salt (Kaskaoutis et al., 2007; Rupakheti et al., 2018). Our results clearly show that the aerosols over both of the sites are dominated by the anthropogenic aerosols.

The scatter diagram between AOD and AE can be helpful for defining the physically interpretable cluster region for sources of different types of aerosols mostly in the location with high aerosol loading (Smirnov et al., 2002; Kaskaoutis et al., 2007). To investigate the major aerosol types, we used the threshold that have been used earlier for nearby site (Delhi, India) (Sharma et al. (2014); Tiwari et al., 2016). The threshold values of AOD and AE for anthropogenic, mixed type, biomass burning and dust were taken as 0.3-1.3 and $>0.9,0.4-0.7$ and $<0.9,>1.3$ and $>0.8$ and $>0.7$ and $<0.6$ respectively. Aerosols with $\mathrm{AOD}$ and $\mathrm{AE}$ values falling into groups other than the above-mentioned categories were considered as undetermined aerosols. However, over both sites, aerosol types were identified as those from anthropogenic activities, biomass burning and mixed (undetermined) in high frequency. During the pre-monsoon and post-monsoon seasons, IGP also experiences extensive forest fire and agro-residue burning (Habib et al., 2006; Ram and Sarin, 2011; Rupakheti et al., 2017) which impacts the distant locations even across the Himalayas in the Tibetan Plateau too (Cong et al., 2015).

In order to provide an example on the variation of aerosol types observed over Lumbini, the scatter plot between AOD and $\mathrm{AE}$ during the pre-monsoon season has been shown in Figure 2.

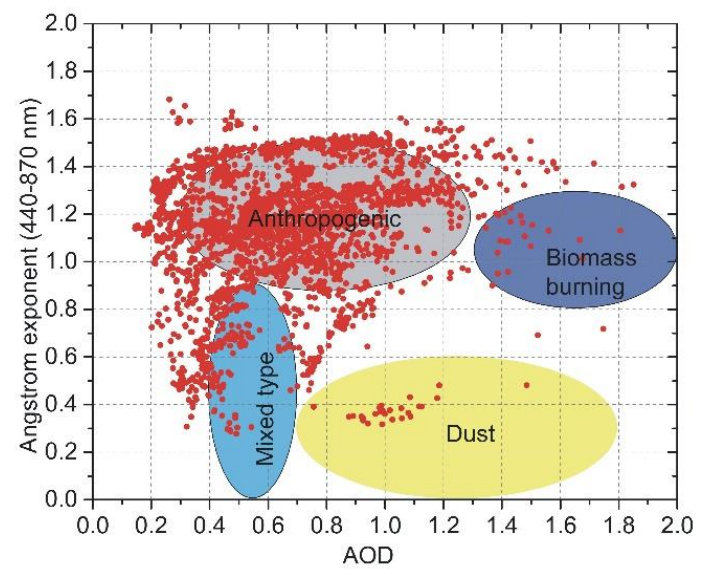

Figure 2. Aerosol types observed in Lumbini during premonsoon season (Rupakheti et al., 2018). 
The aerosol volume-size distribution (VSD) was derived from the sun photometer measurements using 22 radius size bins ranging from 0.05 to $15 \mu \mathrm{m}$. The aerosol VSD has a bi-modal distribution which can be defined by the sum of two lognormal distributions, as governed by the Equation (1) given below:

$$
v(r)=\frac{d V(r)}{d \ln r}=\sum_{i=1}^{2} \frac{C_{v, i}}{\sqrt{2 \pi \sigma_{i}}} \exp \left[\frac{-\left(\ln r-\ln r_{v, i}\right)}{2 \sigma_{i}^{2}}\right]
$$

where, $\mathrm{C}_{\mathrm{v}, \mathrm{i}}$ is the volume concentration for fine-mode and coarse-mode aerosols, $\sigma_{\mathrm{i}}$ is the geometric standard deviation for mode $i$, and $\mathrm{r}_{\mathrm{v}, \mathrm{i}}$ is the volume mean radius. Regarding the volume size distribution, clear bi-modal distribution of aerosol volume size was observed with highest volume concentration during the post-monsoon season in fine mode and pre-monsoon season in coarse mode (in Lumbini) whereas highest value in both modes during pre-monsoon season in Kathmandu. For Lumbini, the fine mode spreads between 0.1 and $1 \mu \mathrm{m}$ with a peak centered between 0.1-0.4 $\mu \mathrm{m}$, while the coarse mode ranges from 1 to $10 \mu \mathrm{m}$ with a peak centered between 2 to $5 \mu \mathrm{m}$. Whereas in the case of Kathmandu, the extension of fine and coarse mode was similar to that of Lumbini but the peaks were centered between 0.1-0.3 $\mu \mathrm{m}$ and 3-6 $\mu \mathrm{m}$ respectively.

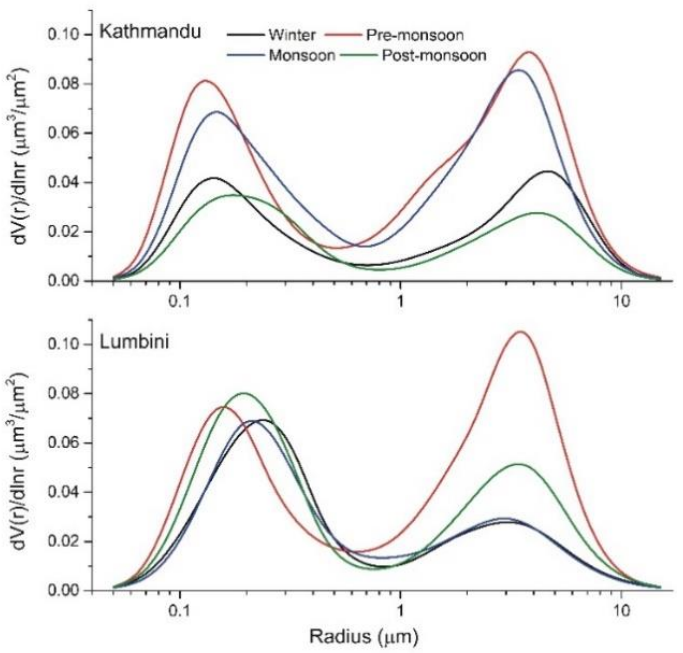

Figure 3. Seasonal aerosol volume size distribution over Lumbini and Kathmandu.

Single scattering albedo (SSA) is the measure of light extinction due to scattering by aerosols for which the value ranges between zero (pure absorbing) and one (pure scattering). In Lumbini (Figure 4), the SSA decreased visibly with increasing wavelength during post-monsoon indicating the presence of light absorbing aerosols. The highest SSA at $675 \mathrm{~nm}$ was found during the monsoon season $(0.93 \pm 0.05)$ indicating the dominance of scattering aerosols. On the other hand, the lowest SSA was found in the post-monsoon season $(0.82 \pm 0.04)$. Another recent study (Wan et al., 2017) has also reported the highest concentration of light-absorbing aerosols like elemental carbon (EC) in total suspended particulate matter during post-monsoon as compared with that in other seasons. However, in the case of Kathmandu, post-monsoon season possess highest SSA $(0.92 \pm 0.03)$ whereas pre-monsoon season, similar to Lumbini, possess lowest SSA $(0.83 \pm 0.04)$ which clearly suggest the presence of light absorbing aerosols during pre-monsoon season over wide region.

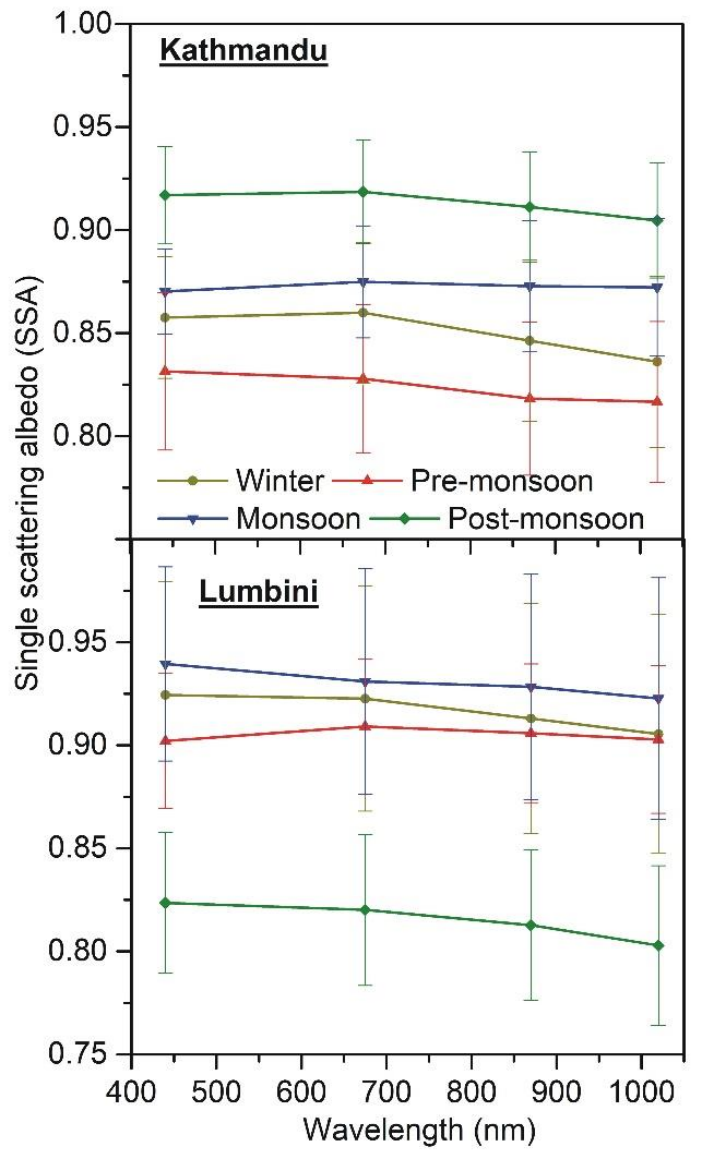

Figure 4. Single scattering albedo over two sites.

The asymmetry parameter $(g)$ is the angular distribution of light scattered by aerosol particles with the value of $g$ ranging from -1 (radiation is entirely backscattered) to +1 (entirely forward scattered radiation), and is dependent, just like SSA upon the size and composition of the particles in the atmosphere (Andrews et al., 2006; Tiwari et al., 2015). Over both sites, during winter, monsoon and post-monsoon seasons, the $g$ value decreased monotonically over both visible and infrared spectral regions but in the case of premonsoon season slightly increased over IR region. Tiwari et al. (2015) mentioned that for dust or polluted continental aerosols the asymmetry parameter decreases with increasing wavelength in the visible range and increases slightly in the near infrared region. However, the overall decrease in the asymmetry parameter during winter, monsoon and post-monsoon season indicates the presence of fine particles (anthropogenic) in the atmosphere. The average $g$ value ranges from $0.71-0.75$ at $440 \mathrm{~nm}$ whereas 
between $0.59-0.63$ at $1020 \mathrm{~nm}$ for Lumbini and 0.70-0.74 and 0.61-0.64 at respective two channels for Kathmandu. A similar pattern of spectral change and extent of $g$ values in $1020 \mathrm{~nm}$ channel has been identified as either black carbon enriched or organic carbon enriched aerosols in the IGP (Tiwari et al., 2015). The highest $g$ values at both of the aforementioned channels (440 $\mathrm{nm}$ and $1020 \mathrm{~nm}$ ) were observed during monsoon season and lowest values were

\section{SUMMARY}

Aerosol optical properties were studied over two sites located in the foothills of the central Himalayas. Average AOD during 2013-2014 was found to be $0.64 \pm 0.41$ (Lumbini) and $0.45 \pm 0.30$ (Kathmandu) whereas average AE was found to be: $1.25 \pm 0.24$ and $1.26 \pm 0.18$ respectively for two sites. Based on the relationship between AOD and AE, aerosol types were identified as those from anthropogenic activities, biomass burning and mixed (undetermined) in high frequency. Clear bi-modal distribution of volume size distribution of aerosols was observed over both sites signifying the presence of aerosols from both anthropogenic and natural sources. Single scattering albedo and Asymmetry parameter analyses indicated the presence of anthropogenic aerosols over both sites. Present study clearly quests for long-term investigation to understand and characterize the nature of aerosols by establishing multiple sites over this research gap zone from where the aerosols gets advected towards the Himalayas and Tibetan Plateau.

\section{References}

Andrews, E., Sheridan, P., Fiebig, M., McComiskey, A., Ogren, J., Arnott, P., Covert, D., Elleman, R., Gasparini, R., Collins, D., 2006. Comparison of methods for deriving aerosol asymmetry parameter. Journal of Geophysical Research 111, 1-16.

Cong, Z., Kang, S., Kawamura, K., Liu, B., Wan, X., Wang, Z., Gao, S., Fu, P., 2015. Carbonaceous aerosols on the south edge of the Tibetan Plateau: concentrations, seasonality and sources. Atmospheric Chemistry and Physics 15, 1573-1584.

Ganguly, D., Jayaraman, A., Rajesh, T.A., Gadhavi, H., 2006. Wintertime aerosol properties during foggy and nonfoggy days over urban center Delhi and their implications for shortwave radiative forcing. Journal of Geophysical Research 111, 1-15.

Gautam, R., Hsu, N.C., Tsay, S.C., Lau, K.M., Holben, B., Bell, S., Smirnov, A., Li, C., Hansell, R., Ji, Q., Payra, S., Aryal, D., Kayastha, R., Kim, K.M., 2011. Accumulation of aerosols over the Indo-Gangetic plains and southern slopes of the Himalayas: distribution, properties and radiative effects during the 2009 pre-monsoon season. Atmospheric Chemistry and Physics 11, 12841-12863.

Habib, G., Venkataraman, C., Chiapello, I., Ramachandran, S., Boucher, O., Shekar Reddy, M., 2006. Seasonal and interannual variability in absorbing aerosols over India derived from TOMS: Relationship to regional meteorology and emissions. Atmospheric Environment 40, 1909-1921. observed during pre-monsoon (post-monsoon at highest wavelength), suggesting the presence of anthropogenic or absorbing aerosols in abundance. In addition, a similar pattern was also observed over other sites in IGP which indicated the presence of black carbon enriched aerosols (Tiwari et al., 2015).

\section{ACKNOWLEDGEMENTS}

This study is supported by National Natural Science Foundation of China (41630754 and 41721091), Chinese Academy of Sciences (QYZDJ-SSW-DQC039) and the State Key Laboratory of Cryospheric Science (SKLCS-ZZ-2017). Maheswar Rupakheti acknowledges the support provided by the Institute for Advanced Sustainability Studies (IASS) which is funded by the German Federal Ministry for Education and Research (BMBF) and the Brandenburg Ministry for Science, Research and Culture (MWFK). The authors acknowledge Christoph Cüppers and Michael Pahlke of the Lumbini International Research Institute (LIRI) for providing the space and power to run the instruments at the LIRI premises and Bhogendra Kathayat, Bhoj Raj Bhatta and Shyam Kumar Newar for their support in operation of the sites.

Holben, B.N., Eck, T.F., Slutsker, I., Tanré, D., Buis, J.P., Setzer, A., Vermote, E., Reagan, J.A., Kaufman, Y.J., Nakajima, T., Lavenu, F., Jankowiak, I., Smirnov, A., 1998. AERONET-A Federated Instrument Network and Data Archive for Aerosol Characterization. Remote Sensing of Environment 66, 1-16.

Kaskaoutis, D., Kambezidis, H., Hatzianastassiou, N., Kosmopoulos, P., Badarinath, K., 2007. Aerosol climatology: on the discrimination of aerosol types over four AERONET sites. Atmospheric Chemistry and Physics Discussions 7, 6357-6411.

Kaufman, Y.J., Tanré, D., Boucher, O., 2002. A satellite view of aerosols in the climate system. Nature 419, 215-223.

Kedia, S., Ramachandran, S., Holben, B.N., Tripathi, S.N., 2014. Quantification of aerosol type, and sources of aerosols over the Indo-Gangetic Plain. Atmospheric Environment 98, 607-619.

Ram, K., Sarin, M.M., 2011. Day-night variability of EC, OC, WSOC and inorganic ions in urban environment of Indo-Gangetic Plain: Implications to secondary aerosol formation. Atmospheric Environment 45, 460-468.

Ramanathan, V., Crutzen, P.J., Kiehl, J.T., Rosenfeld, D., 2001. Aerosols, climate, and the hydrological cycle. Science 294, 2119-2124. 
Ramanathan, V., Crutzen, P.J., 2003. New Directions: Atmospheric Brown "Clouds". Atmospheric Environment $37,4033-4035$

Rosenfeld, D., 2000. Suppression of rain and snow by urban and industrial air pollution. Science 287, 1793-1796.

Rupakheti, D., Adhikary, B., Praveen, P.S., Rupakheti, M., Kang, S., Mahata, K.S., Naja, M., Zhang, Q., Panday, A.K., Lawrence, M.G., 2017. Pre-monsoon air quality over Lumbini, a world heritage site along the Himalayan foothills. Atmospheric Chemistry and Physics 17, 1104111063.

Rupakheti, D., S. Kang, M. Rupakheti, Z. Cong, L. Tripathee, A. Panday, B. Holben. 2018. Observation of optical properties and sources of aerosols at Buddha's birthplace, Lumbini, Nepal. Environmental Science and Pollution Research. doi: 10.1007/s11356-018-1713-z.

Sharma, M., Kaskaoutis, D.G., Singh, R.P., Singh, S., 2014. Seasonal variability of atmospheric aerosol parameters over Greater Noida using ground Sunphotometer observations. Aerosol and Air Quality Resarch 14, 608-622.

Smirnov, A., Holben, B.N., Dubovik, O., O'Neill, N.T., Eck, T.F., Westphal, D.L., Goroch, A.K., Pietras, C., Slutsker, I., 2002. Atmospheric aerosol optical properties in the Persian Gulf. Journal of the Atmospheric Sciences 59, 620-634.

Srivastava, A.K., Tiwari, S., Devara, P.C.S., Bisht, D.S., Srivastava, M.K., Tripathi, S.N., Goloub, P., Holben, B.N., 2011. Pre-monsoon aerosol characteristics over the IndoGangetic Basin: implications to climatic impact. Annales Geophysicae 29, 789-804.
Stocker, T., Qin, D., Plattner, G., Tignor, M., Allen, S., Boschung, J., Nauels, A., Xia, Y., Bex, B., Midgley, B., 2013. IPCC, 2013: climate change 2013: the physical science basis. Contribution of working group I to the fifth assessment report of the intergovernmental panel on climate change.

Tiwari, S., Srivastava, A.K., Singh, A.K., Singh, S., 2015. Identification of aerosol types over Indo-Gangetic Basin: implications to optical properties and associated radiative forcing. Environmental Science and Pollution Research 22, 12246-12260.

Tiwari, S., Tiwari, S., Hopke, P., Attri, S., Soni, V., Singh, A.K., 2016. Variability in optical properties of atmospheric aerosols and their frequency distribution over a mega city "New Delhi," India. Environmental Science and Pollution Research 23, 8781-8793.

Tripathee, L., Kang, S., Rupakheti, D., Cong, Z., Zhang, Q., and Huang, J. 2017. Chemical characteristics of soluble aerosols over the central Himalayas: insights into spatiotemporal variations and sources. Environmental Science and Pollution Research 24 (31): 24454-24472.

Wan, X., Kang, S., Li, Q., Rupakheti, D., Zhang, Q., Guo, J., Chen, P., Tripathee, L., Rupakheti, M., Panday, A.K., Wang, W., Kawamura, K., Gao, S., Wu, G., Cong, Z., 2017. Organic molecular tracers in the atmospheric aerosols from Lumbini, Nepal, in the northern Indo-Gangetic Plain: Influence of biomass burning. Atmospheric Chemistry and Physics 17, 8867-8885. 